\title{
Inverted Schneiderian Papilloma
}

National Cancer Institute

\section{Source}

National Cancer Institute. Inverted Schneiderian Papilloma. NCI Thesaurus. Code C6871.

A benign neoplasm that arises from the ciliated respiratory mucosa that lines the nasal cavity or paranasal sinuses. It results from the invagination and proliferation of epithelial cells in the underlying stroma. Clinical manifestations include nasal obstruction, epistaxis, and anosmia. It has the tendency to recur and extend to adjacent structures. Inverted papillomas are occasionally associated with the development or presence of carcinomas, usually squamous cell carcinomas. 